\title{
The Intellectual Component of Labor Potential as a Factor of Sustainable Development of the Agricultural Sector
}

\author{
Olena Vasyl'yeva ${ }^{1 *}$ and Andrii Karpenko ${ }^{1}$ \\ ${ }^{1}$ National University "Zaporizhzhia Polytechnic", 69063 Zaporizhzhia, Ukraine
}

\begin{abstract}
In the article, the proposition is substantiated that the current development of the agricultural sector is possible on condition of harmonization of environmental, social and economic factors based on the principles of consistency, balance and social justice. The paper examines the impact of the intellectual component of labor potential on economic growth in the agricultural sector. The study of the main types of production functions for macroeconomic analysis is conducted. The advantages of using the CobbDouglas production function in determining the levers of agricultural production growth in the context of sustainable development are substantiated. The present-day priority of activities intellectualization in the agricultural sector is proved. It is proposed to particularly focus on the use of intellectual assets of human potential for agricultural production intensification. The accomplished modeling of the agricultural sector sustainable development gives grounds for an optimistic forecast as to increasing the resource potential of agricultural production due to a growth in the quantitative and qualitative indicators of labor potential.
\end{abstract}

\section{Introduction}

The main purpose of sustainable development is to provide the population of the world with food, therefore, the problem of sustainable development for the agricultural sector is utterly relevant and developed at the sectoral level. We believe that it is the agricultural sector that is concerned with environmental and food issues most, since it is a complex system of agricultural production, environment and rural population.

Not only does the sustainable development of the agricultural sector in Ukraine ensure food security, which is a constituent of the state's economic security, but it also provides for the development of the economy as a whole. A necessary condition for sustainable development is positive dynamics of the economic potential of the agricultural sector, which is a set of all available means, opportunities, productive forces, resources, reserves and competencies that can be used in production activities and may utilize market opportunities in order to achieve the goals of society's socio-economic development.

The content of sustainable development can be determined through formation of appropriate potentials of its components:

- the economic potential of sustainable development (a system of industrial relations that uses environmentally and socially dangerous means of production, safe resource-saving technologies; organization of production aimed at coordinating the economic, social and environmental outputs);

- the environmental potential ("the ability of an ecosystem to continuously restore itself in those qualitative parameters that meet the requirements of social and economic development", whose basis is ensuring the conditions for restoration of natural resources, economical use of non-renewable resources and preservation of biological diversity);

- the social potential of sustainable development (human potential, human and intellectual capital, social consciousness, social infrastructure, social policy). A special role is assigned to accumulation of human capital within the framework of the theory of endogenous growth by improving the levels of education and science, creating and using new technologies and innovations, and developing corporate culture. In modern conditions, it is an effective corporate culture that not only performs the function of favorable social environment formation, but also attracts and maintains talents, develops human capital [1]. Sustainable economic growth is based on knowledge, creativity (formulation of new ideas and their use to create cultural products and works of art, a capability of creating new technologies and making inventions) and access to information as components of the social potential of sustainable development [2].

We believe that the determining factor for achieving the goals of the agricultural sector's sustainable development is a system approach, according to which the components of sustainable development should develop in a comprehensive and coordinated manner, ensuring the efficient, secure production functioning, preservation and restoration of natural resources, quantitative and qualitative reproduction of labor potential.

In our opinion, the modern paradigm of the concept of the agricultural sector sustainable development fully corresponds to the new economic paradigm "The Economics of Happiness" [3], which grounds on the state of well-being and environment, ensuring of 
material and spiritual satisfaction with life, provided that there is an optimal balance between the needs of society and limited resources. The production of highquality food products within the reasonable use of natural resources is a necessary, but not sufficient, condition for improvement in the quality of life, since non-economic aspects of life determine its duration and quality as well as mental well-being of citizens. A human-centered economics of happiness changes the priorities of social existence and expands the interaction of the sustainable development components. It is the socio-economic model that comes to the fore and determines sustainable economic development: the alternative to the gross domestic product is the Human Development Index, which measures the people's capability of living a long, healthy, creative life. This model further develops the ideas of the Lukas and Romer [4-6] endogenous growth models, according to which the main factor of economic growth is an increase in investments in human capital that ensures the scientific and technological progress.

Informed management decision-making in the context of sustainable development requires use of modern methodological tools for obtaining the results, which are difficult to obtain by applying traditional methods. We assume that in order to analyze the levers for economic growth of the agricultural sector in the context of sustainable development, the most successful model to be applied is the Robert Solow neoclassical growth model with a stable path of balanced development, according to which it is the efficient use of resources and technological progress that are the imperatives of economic growth [7]. The product created in the economy is the result of the following production factors' interrelationship: labor $(L)$, capital $(K)$, land resources and technological progress factors $(N)$, whose impact on the volume of the total output can be described with the use of production function as one of the ways to forecast the development of complex economic systems.

\section{Results and discussion}

\subsection{Sustainable development factors of the agricultural sector}

Agriculture as a core element of the agrarian sector, which affects overcoming the global problem of hunger as well as maintaining food and environmental security of humanity, has the features that consist "in the use of production means of natural origin: plant and animal organisms, water resources alongside with climate-related resources - light, heat, precipitation, etc." [8]. The use of specific means of agricultural production, which are related to the environment and its natural laws in a complimentary way, limits the opportunities for economic growth. The ambiguous impact of external conditions on agricultural production can be compensated by internal factors, which include use of advanced technologies, availability of qualified personnel, efficiency of personnel use and their work motivation.

In our opinion, the manifestation of the components of the triune concept of sustainable development economic, environmental and social, can be represented by the unity of three types of capital: physical (production), natural and human, which is formed, accumulated and realized in the agricultural production, agrarian landscape through labor potential.

The economic component of sustainable development of the agricultural sector provides for a constant increase in the volume of agricultural production and improvement of its quality, strengthening of the production potential, creation of a rational production structure, maintaining of an appropriate level of financial stability, increase in the labor productivity, establishment of an appropriate market infrastructure, improvement of the model for investment support and tax policy.

The environmental component of sustainability should ensure the integrity and restoration of natural capital, compliance with the agricultural and environmental production standards, ability of the ecosystem to self-regenerate, optimization of the agrarian landscape structure, improvement of the acreage and crop rotation structure, increase in soil fertility, reduction of the environmentally destructive impact of agricultural production on the agrarian landscape and environmental pollution, prevention of the negative impact of degraded land on the health and well-being of the population.

The social component is focused on the development of human capital, maintenance of the number of employed population and reduction of unemployment in agricultural production, stabilization of the demographic situation, improvement in the level and quality of life, development of the social infrastructure, rural areas and communities, improvements in the administrative and territorial structure, accessibility of healthcare in rural areas, increase in incomes of rural population.

Sustainable development of the agricultural sector is possible on condition that environmental, social and economic factors are harmonized on the basis of consistency, balance and social justice. The transition to sustainable development, to a new paradigm for society development, makes relevant the issue of rational use of all types of resources in the process of product creation in the economy. Agricultural produce occupy a significant share in the structure of generating gross value added, which gives the grounds to state about the prospects for increasing the sales volume of exported agricultural produce, provided that the interrelationship of production factors is optimal [9].

\subsection{The main types of production functions in macroeconomic analysis}

The impact of labor potential on the quantity of output goods can be described by the following production function equation: 


$$
Y=f(K, L, N)
$$

The components in this equation (factors of economic growth) are represented in one form or another by: the total amount of production assets used $\mathrm{K}$ (the area of farmland, number of fixed and production assets in value form), the total cost of labor $\mathrm{L}$ (the number of workers employed in agriculture, cost of working time) and other predictors that take account of the technological progress $\mathrm{N}$. In this form, the production function only characterizes a quantitative impact of one or more production factors on the output volume whereas a growth in production volumes due to extended use of all types of resources (extensive economic growth) is very limited. In the modern economic theory, the main role among the production factors belongs to such factors as labor, land, capital and entrepreneurial capabilities.

The production function can be represented in various forms, from a linear dependence on a single production factor to the complex systems described by recurrent equations that relate the system state at different time intervals.

The main types of production functions used in theoretical and applied macroeconomic analyses are as follows:

1) the linear function: $Y=a_{1} x_{1}+a_{2} x_{2}+\ldots+a_{n} x_{n}$. This model for estimating the parameters $a_{1}, a_{2}, . . a_{n}$ characterizes the marginal increase in the final value depending on the marginal increase in each resource per unit and in the units, in which they are presented in the input data (with unlimited elasticity of resource substitution);

2) the Cobb-Douglas aggregated function: $Y=a_{0} K^{a_{1}} L^{a_{2}} \ldots X^{a_{n}}$. The model for estimating parameters $a_{1}, a_{2}, . . a_{n}$ characterizes the elasticity of production by resources, that is, the quantitative relationship between production volumes as provided by resources in relative (percentage) measurement (elasticity of resource substitution equals 1 );

3) the Leontief function $Y=A \min \left(\frac{K}{K_{0}} ; \frac{L}{L_{0}}\right)$ represents a production function with constant ratios of production factors (with zero elasticity of resource substitution);

4) the CES function: $Y=A\left(\sum_{i=1}^{m} a_{i} x_{i}^{-b}\right)^{-h / b}$ represents a production function with constant resource substitution elasticity.

The most common among the production functions is the Cobb-Douglas production function, which models the relationship between the output (or another final indicator) and volumes of production factors as the product of the volumes of applied values with certain power coefficients. According to $[10,11]$, in the classical Solow growth model, it is advisable to apply the production function in the form of the CobbDouglas function, where the possibility and limitation of factor substitution are essential. R. Solow's contribution to the practice of using production functions consisted in modifying the Cobb-Douglas production function and extending it, in addition to labor $(L)$ and capital $(K)$, with the third factor technological progress, which became the main reason for the development of the US economy in the first half of the XX century. According to R. Solow [12], only $12.5 \%$ of the growth in labor productivity during this period could be attributed to an increase in capital and the number of employees, whereas $87.5 \%$ was the result of the changes in the quality characteristics of labor potential and improvement of labor organization (professional development of employees, improvements in production organization, etc.).

In our opinion, today there is no practice of a widespread use of the Cobb-Douglas production function in management of labor potential; some elements of mathematical modeling are only applied, with the regression equation being used. It is the parameters of the Cobb-Douglas function equation that allow us to find answers to the questions "to what extent", "to what degree", "why", which, as we believe, furnishes grounds for development of adequate management models for production resources in the agricultural sector [13].

\subsection{Justification of the possibility of the Cobb- Douglas production function use in determining the levers for agricultural production growth in the context of sustainable development}

In addition to economic results, sustainable development implies an environmental effect as well as consideration of environmental impacts on economic development of the industry. We believe that conclusion as to the use of the environmental and economic balance, application of a production optimization model with consideration of efficient use of production resources and minimization of amounts of pollutant emissions deserves attention [14]. Therefore, it is quite appropriate to use an environmental and economic production function, which may include an environmental component as the external factor that affects output adversely. The methodology for forming and verifying a production function allows determination of the optimal combination of all resources for gaining maximum profits [15].

The advantages of the Cobb-Douglas production function are as follows:

- a relative simplicity of functional dependence, which makes it easy to determine the indicators of labor productivity and fund returns, elasticity of outputs in all parameters, margins for resource substitution;

- practical universality and adequacy: a possibility to determine the contribution of each factor to the total production output, intensive and extensive factors of economic growth, practical application in labor potential management; 
- macroeconomic orientation: based on the actual economic indices of official statistical reports and can be easily parameterized with the use of the correlation and regression analysis;

- feasibility: functional dependence of output on costs is non-linear and does not contain the disadvantages characteristic of linear production functions that describe the processes of an ideal economy.

But, despite the above advantages, the production function also has a number of disadvantages [13]:

- the production function with a constant scale effect may not adequately reflect the production process (under conditions of intensive growth of production factors, the scale effect is greater than 1);

- it is based on the assumption that production resources are fully substitutional;

- determination of the production function parameters is based on the marginal prices of factors that are equal to average prices and are calculated on the basis of market prices, which is possible in the context of perfect competition and market equilibrium and does not "work" in the actual economics;

- the principle of complementarity, which takes into account the capital structure, is ignored.

\subsection{Intellectual assets of human potential as a factor of intensification of agricultural production}

At the end of the XX century, the pace of economic development in the leading countries of the world was mainly stipulated by contribution of the intensive factors associated with the emergence of new technologies rather than by the number of people employed and increase in investments. American economists G. Mankiw, D. Romer and D. Weil proposed that the quality of labor force should be taken into account in the model of economic growth, introducing the factor of intellectual capital, which included the cost of education, publication of scientific literature, construction, material and technical resources of educational institutions, etc. [16]. In the theory of economic growth, P. Romer [17] distinguished two different types of production factors: tangible and intangible. The scientist believed that the emergence of new ideas and technologies (intangible resources) leads to the transformation of material resources into more valuable ones. S. Oliner and D. Sichel, based on the analysis of the reasons for the 1995-1999 acceleration of scientific and technological progress in the United States and on the assessment of the production function parameters, considered information technologies to be a separate significant factor of economic growth [18]. Modification of the production function and consideration of the qualitative parameters of labor potential have resulted from the emergence of the ideas of human capital accumulation at the end of the XX century, which became the basis for models of endogenous scientific and technological progress, according to which technology and knowledge are a public good, and technological progress is the result of knowledge accumulation.

Since human capital is defined as individuals' knowledge, education and competences in the implementation of national goals and objectives (mainly based on intangible resources and hidden opportunities), the model of its assessment should include qualitative and quantitative indicators. At the same time, the development potential is represented by intellectual capital, which is considered a key factor for success [19].

Not only have the large-scale and multi-vector changes of recent decades transformed a significant part of the world's socio-economic processes, but they have also expanded and deepened the existing risks. The rate of changes has accelerated significantly, and competitiveness has increasingly become determined by the intellectual grounds of capital. It is an economically active person who is the main basis for innovative changes and economic development.

Today, we observe intellectualization of the economy, with an objective process of expanding the conditions for using people's intellectual and creative abilities being underway, with scientific knowledge and specialized unique skills of their possessors becoming the main source and key factor in the development of material and non-material production, in ensuring sustainable economic development. It is determined that the educational, intellectual, and creative potentials of a person are not only a powerful factor of economic growth, but also a source of income at all levels: of a person, of an enterprise and of a state.

The results of studying various approaches to the definition and structuring of human potential allow us to state that the majority of them consider the intellectual component to be the most essential. The due regard for this component and its analysis enables distinguishing intellectual assets, that is, exactly that part of human potential that can be further capitalized and is capable of ensuring creation of added value which will determine the competitiveness level at both micro and macro levels in the future.

In our opinion, intellectual assets can be defined as an economic category that reflects the process of transformation of part of human potential capable of development and changes into other capital of economic units. Intellectual assets represent an integrated category that includes the intellectual capital objects already reflected in accounting (intangible assets), and those that should be included in the accounting system (customer relations, marketing, technology improvement, training and development of personnel, development of new products and services).

It is determined that intellectual assets are a universal resource with a unique character in terms of increasing the income and value of an enterprise. Intellectual assets act as a form of embodiment of possible future benefits and can make profits. The intellectual assets' capability of bringing economic benefits is one of the main conditions for their involvement into economic turnover. The possibility of alienating these assets to other entities by transferring 
different amounts and nature of rights enables their wider use in the process of commercialization through involvement of necessary economic entities. Thus, formation of intellectual assets and their effective use is an important strategic area of a company's development, which should be taken into account when drawing up financial budgets and disseminating information about the company's activities. Accounting for intellectual assets contributes to capitalization of the company, maximizing its market value. An increase in the company's value contributes to ensuring sustainability and further development through a greater opportunity to attract investment resources.

Intellectual assets of human potential can be defined both as individual elements of human potential and outcomes of this potential capitalization in activities. These are separate elements of human potential that gradually accumulate and transform starting from the very birth of a person during his/her upbringing, cultural development and involvement in a healthy lifestyle, while obtaining education and professional training, and also these are intellectual outcomes of human activities. Intellectual assets of human potential are considered as competencies (cognitive, emotional, creative), since they have an intangible nature, and as outcomes of intellectual activities (intangible and tangible forms) [20].

The intellectual assets of the human potential in Ukraine are estimated by the following indicators:

- the share of employees engaged in professional, scientific and technical activities to the total number of employees, \%;

- the share of those employed in education to the total number of employees, $\%$;

- the share of candidates and doctors of sciences in the total number of employees, \%;

- the share of employees involved in scientific research and development in the total number of employees, \%;

- the number of researchers per 1000 people of the employed population (aged 15-70), persons;

- the ratio of the average number of employees who used a computer with internet access to the average number of employees who used a computer, \%);

- the number of people using broadband internet access, per 100 people of the population, persons;

- the specific weight of innovative products sold in the industrial production volume, $\%$;

- the number of patents for inventions received per 1 million people, units;

- the number of utility patents received per 1 million people, units;

- the number of design patents received per 1 million people, units;

- the number of certificates for trademarks and service marks per 1 million people, units;

- the number of patents received in the United States per 1 million people, units.

The measurement of these indicators enabled determination of the integral coefficients for the intellectual assets of Ukraine's human potential [20].

\subsection{Modeling of sustainable development of the agricultural sector based on labor potential}

Given the complex structure of labor potential, which includes intellectual components that characterize the ability to innovate, entrepreneurial and creative abilities, educational level, professional experience [21], we believe that in the context of sustainable development of the agricultural sector, it is advisable to use a four-factor Cobb-Douglas function, which takes into account not only the quantity but also the quality of labor as well as the environmental factor of impact:

$$
Y=a_{0} K^{a_{1}} L^{a_{2}} I^{a_{3}} E^{a_{4}}
$$

where $Y$ stands for the efficiency indicator (output);

- $K$ - the amount of fixed capital or the amount of fixed assets used (capital investments);

$-L-$ labor costs (the number of people employed in agriculture);

$-I-$ integral coefficient of intellectual assets;

$-E$ - pollutant emissions;

$-a_{0}-\mathrm{a}$ technological coefficient that characterizes production efficiency, takes into account complex influence of qualitative determinants of labor potential, impact of the factors which cannot be quantified (the indicator of technological progress);

$-a_{i}$ - elasticity coefficients that characterize the effect of capital, labor and intellectual asset growth as well as pollutant emissions on $Y$ output growth (i.e., $a_{i}$ is a fraction of the factors) [22].

The sum of the elasticity coefficients $a_{1}+a_{2}+\ldots+$ $a_{n}$ characterizes the effect of production scale: the effect is growing, if $a_{1}+a_{2}+\ldots+a_{n}>1$ (intensive economic growth), the increase in production outgoes the growth of factor costs; the effect is constant, if $a_{1}+$ $a_{2}+\ldots+a_{n}=1$ (extensive economic growth), the increase in production volumes is not affected by production scale factors; the effect is receding, if $a_{l}+$ $a_{2}+\ldots+a_{n}<1$ (lack of economic growth), the increase in factor costs is accompanied by a slowdown in growth of production volumes.

When conducting an empirical study of the agricultural sector of the economy and forming the production function, we used the dependence that shows the relationship between the volumes of the fixed production resources use (labor, capital, intellectual assets and pollutant emissions) and the output. Since the main indicator of the industry's degree of development in a market economy is value added, which reflects a possibility of production expansion, the gross value added of agriculture was considered as the efficiency indicator.

The statistics shown in Table 1 were used to calculate the Cobb-Douglas production function with the gross value added as the efficiency indicator.

Having made the calculations with the use of the linear regression analysis based on the least squares method, the values of the Cobb-Douglas function coefficients were determined. The resulting production function is thus [23]: 


$$
Y=422388 K^{0,34474} L^{2,63344} I^{1,60806} E^{-2,86638}
$$

Table 1. The statistics for calculating the production function

\begin{tabular}{|c|c|c|c|c|c|}
\hline $\begin{array}{c}\boldsymbol{T}, \\
\text { year }\end{array}$ & $\begin{array}{c}\boldsymbol{Y}(\boldsymbol{T}), \\
\text { UAH } \\
\text { million }\end{array}$ & $\begin{array}{c}\boldsymbol{K}(\boldsymbol{T}), \\
\text { UAH } \\
\text { million }\end{array}$ & $\begin{array}{c}\boldsymbol{L}(\boldsymbol{T}), \\
\text { thousand } \\
\text { persons }\end{array}$ & $\boldsymbol{I}(\boldsymbol{T})$ & $\begin{array}{c}\boldsymbol{E}(\boldsymbol{T}), \\
\text { thousand } \\
\text { tons }\end{array}$ \\
\hline 2008 & 65148 & 16682 & 3322,1 & 0,5 & 7210,3 \\
\hline 2009 & 65758 & 9295 & 3152,2 & 0,5 & 6442,9 \\
\hline 2010 & 82948 & 11311 & 3115,6 & 0,6 & 6678,0 \\
\hline 2011 & 109961 & 17981 & 3410,3 & 0,6 & 6877,3 \\
\hline 2012 & 113245 & 18564 & 3506,7 & 0,6 & 6821,1 \\
\hline 2013 & 132354 & 18175 & 3389 & 0,6 & 6719,8 \\
\hline 2014 & 161145 & 18388 & 3091,4 & 0,6 & 5346,2 \\
\hline 2015 & 239806 & 29310 & 2870,6 & 0,5 & 4521,3 \\
\hline 2016 & 279701 & 49660 & 2866,5 & 0,5 & 4498,1 \\
\hline 2017 & 303949 & 63401 & 2860,7 & 0,5 & 3879,1 \\
\hline 2018 & 360757 & 65059 & 2937,6 & 0,4 & 3866,7 \\
\hline
\end{tabular}

Calculated by the authors on the basis of $[20,24]$

To evaluate the calculated production function (3), the regression analysis parameters were analyzed. According to the calculations, the multiple correlation coefficient is $\mathrm{R}=0.983$, the standard approximation error is 0.148 . The calculated value of the Fischer Fcriterion equals 46.71 and is greater than the table value of the Fischer F-criterion (with 99\% confidence probability, reliability), which is 8.45 . Therefore, the resulting regression equation can be recognized as significant. This means that with a probability of $99 \%$, the found Cobb-Douglas production function (3) corresponds to the input data of the problem.

The production function formed has reliable statistical characteristics. The value of the multiple correlation coefficient proves a closest relationship between the efficiency indicator and the selected factors; $98.3 \%$ of the variation in gross value added depends on the fluctuations of the factors included in the equation, and only $1.7 \%$ could be attributed to the factors that are not taken into account. The value of the coefficient of determination $R^{2}(0.966)$ is quite close to 1 , so the regression model is successful, and the relationship between the resulting indicator of the production function and the input factors is strong. The $96.6 \%$ variance in the output $Y(T)$ is due to the regression of the selected levers of influence $(K, L, I$, $E)$. This confirms that the model considers the most important factors.

Thus, the formed equation (3) meets all the requirements and can be used for economic analysis (Table 2).

Table 2. The results of the production function modeling

\begin{tabular}{|c|c|}
\hline Parameters & $\boldsymbol{Y}(\boldsymbol{T})$ - gross value added \\
\hline function & $Y=422388 K^{0,34474} L^{2,63344} I^{1,60806} E^{-2,86638}$ \\
\hline$a_{0}$ & 422388 \\
\hline$a_{1}$ & 0,34474 \\
\hline$a_{2}$ & 2,63344 \\
\hline$a_{3}$ & 1,60806 \\
\hline$a_{4}$ & $-2,86638$ \\
\hline$\left(a_{1}+a_{2}+a_{3}+a_{4}\right)$ & 1,72 \\
\hline
\end{tabular}

The analysis showed that the growth of quantitative and qualitative indicators of the agricultural sector's labor potential has a direct impact on the increase in the gross value added of agricultural produce, since there is a direct relationship between them. Respectively, sustainable development of the agricultural sector of the economy is possible on the basis of the endogenous technological progress, which is considered to be the result of purposeful human activities, whose driving force is the intellectual assets of human potential.

\section{Conclusions}

The econometric analysis using the Cobb-Douglas production function, that takes into account environmental, social and economic factors, showed that, first and foremost, the economic growth in the agricultural sector is associated with an improvement in the quantitative and qualitative characteristics of labor potential (the number of employed people and intellectual assets respectively); and secondly, it is associated with an increase in capital investments and a decrease in the amount of pollutants emitted.

The economic growth of agricultural production is labor-intensive, since $\left(a_{2}>a_{1}\right)$ depends significantly on the quantitative indicators of the rural labor potential $\left(a_{2}\right)$, which are gradually decreasing. It is caused by the negative demographic trends, which, in turn, are a consequence of the decline of rural areas and reduction in employment and income of the population in rural areas. In our opinion, the results obtained with regard to the growing effect of scale give grounds for an optimistic forecast as to increasing the resource potential of agricultural production due to a growth in the quantitative and qualitative indicators of labor potential.

Among the qualitative characteristics of labor potential, special attention should be paid to intellectual assets (cognitive, emotional and creative competencies), which gradually accumulate and transform starting from the very birth of a person during his/her upbringing, cultural development and involvement in a healthy lifestyle, while obtaining education and professional training, and also to the intellectual outcomes of human activities.

\section{References}

1. A. Karpenko, K. Basenko, Highly Effective Corporate Culture as an Instrument of Talents' Attracting and Retaining. Balt. J. of Econ. Stud. 3(4), 101-106 (2017). doi.org/10.30525/22560742/2017-3-4-101-106.

2. V. Antonyuk, I. Pidorycheva, Strat. Pan. 2, 116123 (2017).

3. Iu.Yarmolenko, Theor. \& Pract. Publ. Admin. 2(53), 107-111 (2016).

4. P. M. Romer, J. Econ. Perspect. 8(1), 3-22 (1994).

5. R. E. Lucas, J. Monet. Econ. 22, 3-42 (1988). 
6. C. I. Jones, Paul Romer: Ideas, Nonrivalry, and Endogenous Growth. Scand. J. of Econ. 121(3), 859-883 (2019). doi: 10.1111/sjoe. 12370.

7. R. M. Solow, Quart. J. Econ. 70(1), 65-94 (1956).

8. O. Borodina, Imperatives of complementary development in agrosphere. Econ. \& Forecast. 4, 125-136 (2017). doi.org/10.15407/eip2017.04.125.

9. O. Vasylieva, Factors of Labor Productivity Growth in Agriculture of the Agrarian Region. Balt. J. of Econ. Stud. 3(4), 1-6 (2017). doi.org/10.30525/2256-0742/2017-3-4-1-6.

10. R. M. Solow, Rev. Econ. Stat. (1961), https://msuweb.montclair.edu/ lebelp/ACMSCapL abSubREAS1961.pdf. Accessed 28 Sept 2020.

11. R. Barro, X. Sala-i-Martin, J. Pol. Econ. 100, 223251 (1992)

12. V. Gonda, BIATEC. XIII(11), 22-25 (2005).

13. O. M. Vilchynska, Y. M. Panochyshyn, T. O Kushnir, Her. Khmeln. Nat. Univ. Econ. Sc. 2(1), 177-181 (2016).

14. I. N. Lyashenko, L. Z Khrushch, Econ. Her. Donbas. 16 184-188 (2012).

15. Y. Mundiak, R. Butzer, D. F. Larson, Heterogeneous technology and panel data: The case of the agricultural production function. J. Dev. Econ. 99(1), 139-149 (2012). doi: 10.1016/j.jdeveco.2011.11.003.

16. G. Mankiv, D. Romer, D. Weil, Quart. J. Econ. 107(2), 407-438 (1992).

17. P. Romer, Amer. Econ. Rev. 86(2), 202-206 (1996).

18. D. Oliner, D. Sichel, J. Econ. Pers. 14, 3-22 (2000).

19. M. Kozak, Intellectual Capital as a Key Factor of Socio-Economic Development of Regions and Countries. Procedia Economics and Finance. 6, 288-295 (2013). doi: 10.1016/S22125671(13)00142-1.

20. A. V. Karpenko, Rozvytok intelektual'nykh aktyviv lyuds'koho potentsialu: teoriya ta praktyka (The Development of Intellectual Assets of Human Potential: theory and practice). (FOP V. V. Mokshanov, Zaporizhzhya, 2018)

21. L. V. Shaulska, Strategiya rozvytku trudovogo potencialu Ukrayiny (Development strategy of labor potential of Ukraine), (In-t ekonomiky promyslovosti NAN Ukrayiny, Doneczk, 2005).

22. L. I. Voynicha, Youn. Sc. 3(55), 642-646 (2018).

23. O.Vasyl'yeva, in Organizational problems of life quality management in the conditions of globalization, ed. by M. Duczmal, T. Nestorenko (The Academy of Management and Administration in Opole, Opole, 2020), p.428.

24. Official site of (2020) the State Statistics Service of Ukraine. http://www.ukrstat.gov.ua. Accessed 28 Sept 2020. 